\title{
XPS analysis with pulsed voltage stimuli
}

\author{
Engin Karabudak, U. Korcan Demirok, Sefik Suzer * \\ Bilkent University, Department of Chemistry, Bilkent 06800, Ankara, Turkey
}

Received 18 July 2005; accepted for publication 30 October 2005

Available online 19 December 2005

\begin{abstract}
We record XPS spectra while applying 0 to $+10 \mathrm{~V}$ or 0 to $-10 \mathrm{~V}$ square pulses to the sample rod, which normally results in twinning of all peaks at correspondingly increased (for $+10 \mathrm{~V}$ ) or decreased (for $-10 \mathrm{~V}$ ) binding energies. For poorly conducting samples, like silicon oxide layer on a silicon substrate, the twinned peaks appear at different energies due to differential charging, which also vary with respect to the frequency of the applied pulses. Moreover, the frequency dependence varies with the thickness and can be correlated with the capacitance of the oxide layer. The technique is simple and can lead to extract important information related with dielectric properties of surface structures in a totally non-contact fashion.
\end{abstract}

(c) 2005 Elsevier B.V. All rights reserved.

Keywords: X-ray photoelectron spectroscopy; Differential charging; Silicon dioxide layers; Capacitance

X-ray photoelectron spectra are normally recorded while the samples are electrically tied to the spectrometer ground to avoid disturbances due to contact potentials and/or charging. Even then, positive charging (commonly referred as surface charging or differential charging) is unavoidable in analysis of poorly conducting samples as a result of incomplete neutralization [1-6]. Use of a lowenergy electron flood gun, for neutralization, has been very successful for most applications $[7,8]$. Over-neutralization (using the flood gun) leading to excess negative charging is also encountered.

Utilization of surface charging (mostly negative) phenomenon, for elucidating chemical and/or structural parameters of various materials, has also been reported. Lau and coworkers [9-15] have published several articles, dealing with various structural and electrical properties of ultrathin dielectric films on semiconductors using surface charging. Thomas et al. [16] were able to separate various electrically uncoupled regions on an integrating circuit surface using the surface charging effect; and similar applications were also reported by Ermolieff et al. [17] and Bell

\footnotetext{
* Corresponding author. Tel.: +90 312 2664946; fax: +90 3122664579.

E-mail address: suzer@fen.bilkent.edu.tr (S. Suzer).
}

and Joubert [18]; while Miller et al. applied the technique to separate the XPS signals of the fiber from the exposed matrix at fractured surfaces [19]. Use of surface charging for lateral differentiation of mesoscopic layers and for depth profiling in $1-10 \mathrm{~nm}$ thin layers have also recently been reported [20,21]. By adopting a different strategy, we have also reported that by application of a small (1$10 \mathrm{~V}$ ) bias we can control the differential charging to obtain a variety of analytical information about surface structures [23-25].

The technique of biasing the sample goes back (three decades) to the early days of XPS $[1,2]$. However, use of it for extracting chemical and/or structural information is not extensive. In a recent application Havercroft and Sherwood [22] showed that biasing the sample holder, with a large negative d.c. voltage $(25-100 \mathrm{~V})$, could be used to identify chemical differences in oxide films on an aluminum alloy. In our previous reports we have mainly concentrated on applications using the voltage stress in d.c. form and stated that it was also possible to apply the external voltage stress in pulsed mode without giving much details [23-25]. In this contribution we extend our work to include voltage stress in pulsed mode and show that the frequency dependence gives complementary information. 
Oxide layers are grown thermally on HF-cleaned $\mathrm{Si}(100)$ substrates at $500{ }^{\circ} \mathrm{C}$ in air. Thicknesses of the samples are measured using elipsometry and are further verified by using a stylus profilometer. A Kratos ES300 electron spectrometer with $\mathrm{Mg} \mathrm{K} \alpha \mathrm{X}$-rays (non-monochromatic) is used for XPS analysis. A typical sample is a ca. $2 \mathrm{~mm}$-thick silicon wafer with dimensions of $4 \times 8 \mathrm{~mm}$, which is tied to the sample rod and the voltage stress (d.c. or pulsed) is applied to the sample rod externally. The energy analyzer accepts electrons almost form the entire sample surface area. A filament is also placed within $5 \mathrm{~cm}$ of the sample to supply additional low energy electrons. In the standard geometry the sample accepts X-rays at $45^{\circ}$ and emits photoelectrons at $90^{\circ}$ with respect to its surface plane. Fig. 1 depicts the Si2p region of an HFcleaned $\mathrm{Si}(100)$ sample; (b) recorded by grounding the sample rod, and while applying a continuous (a) 0 to $-10 \mathrm{~V}$, and (c) 0 to $+10 \mathrm{~V}$ pulses at $0.5 \mathrm{~Hz}$ frequency. During one pulse, the sample spends $50 \%$ of its time near ground potential, and $50 \%$ of its time at $+10 \mathrm{~V}$, therefore, all peaks are twinned, at all frequencies applied $(0.1-$ $1000 \mathrm{~Hz}$ ), and with exactly the same energy difference measured $(10.0 \mathrm{eV})$, within the accuracy of our measurements, which we estimate it to be better than $0.1 \mathrm{eV}$.

The situation, however, is very different when the oxide layer is thicker than $2 \mathrm{~nm}$, where the measured energy differences vary with the frequency of the pulse due to differential charging as we will demonstrate now. In order to calibrate the measured energy differences we have also attached a gold metal strip on the sample in electrical contact with the sample rod. In Fig. 2, we show the Si2p-Au4f region of a sample containing ca. $30 \mathrm{~nm}$ thermal oxide layer

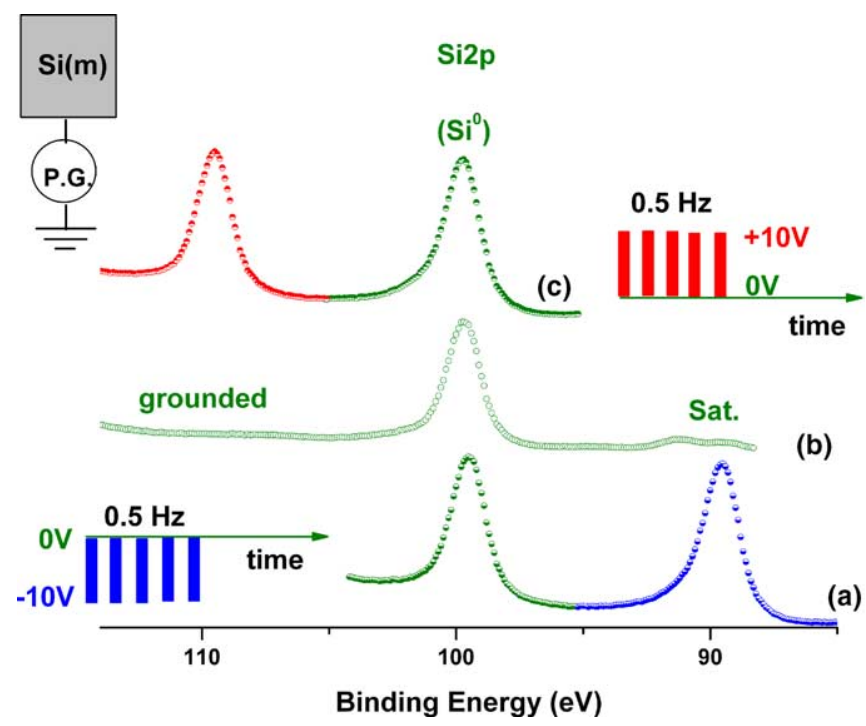

Fig. 1. XPS spectra of the Si2p region of a clean $\mathrm{Si}(100)$ surface recorded by (b) grounding the sample, (a) applying 0 to $-10 \mathrm{~V}$ pulses at $0.1 \mathrm{~Hz}$, and (c) applying 0 to $+10 \mathrm{~V}$ pulses at $0.1 \mathrm{~Hz}$. The $\mathrm{Si}^{0}$ peak is twinned, because when pulsed, the sample experiences the ground and the applied potential $50 \%$ at a time, respectively. Sat. refers to the extra peaks due to the $\mathrm{K} \alpha_{3,4}$ X-ray satellites.

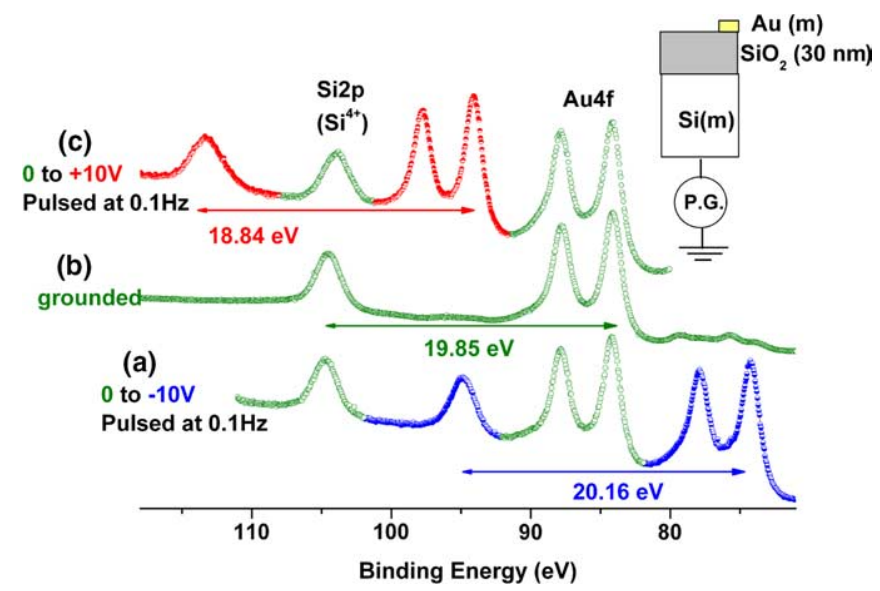

Fig. 2. XPS spectra of the $\mathrm{Si} 2 \mathrm{p}-\mathrm{Au} 4 \mathrm{f}$ region of a silicon sample, containing ca. $30 \mathrm{~nm}$ thermal oxide layer, without and with $0.1 \mathrm{~Hz}$ pulses as in Fig. 1. Both the Au4f doublet and the Si2p of the oxide layer $\left(\mathrm{Si}^{4+}\right)$ are twinned when pulsed. This time the measured binding energy difference between the Au4f and Si2p peaks vary depending on the polarity of the pulses.

without and with positive and negative pulses also at $0.1 \mathrm{~Hz}$. The $30 \mathrm{~nm}$ oxide was chosen for clarity of the presentation, since for thinner samples another peak, due the silicon substrate at $3.4 \mathrm{eV}$ lower binding energy, would also be present to complicate the spectrum. As can also be gathered from the figure, the measured binding energy difference between the $\mathrm{Si} 2 \mathrm{p}$ of the oxide layer $\left(\mathrm{Si}^{4+}\right)$ and the Au4f are different in all the three cases [i.e. (b) grounded, under (a) negative and (c) positive pulses, respectively]. When the sample experiences $-10 \mathrm{~V}(50 \%$ of the time) with negative pulses, the slow stray electrons or electrons from the filament, which would otherwise fall onto the sample and neutralize the positive charges developed in the oxide layer as a result of photoelectron emission, are repelled and the oxide layer is left positively charged to cause the measured binding energy difference to increase. In the case of positive pulses, the low energy electrons are withdrawn onto the sample to neutralize the oxide layer and decrease the measured binding energy difference. In this particular experiment the oxide layer is in fact overneutralized and negatively charged (by the additional electrons from the filament) since the measured $\Delta$ B.E. is $18.84 \mathrm{eV}$, which is smaller than the correct value of $19.4 \mathrm{eV}(103.4 \mathrm{eV}$ for $\mathrm{Si} 2 \mathrm{p}$ of the oxide minus $84.0 \mathrm{eV}$ for Au4f) [29].

Secondly, the measured binding energy difference changes with the frequency of the pulse as shown in Fig. 3. The difference is small at high frequencies, due to the rapid changes of the applied voltage between ground and $+10 \mathrm{~V}$, the oxide layer can not respond and finds itself in a confused average potential throughout the cycle. However, at low frequencies the measured binding energy difference between the Si2p and the Au4f levels under positive pulses becomes smaller when compared to the ground since more time is allocated for the silicon oxide layer to neutralize its positive charge. 


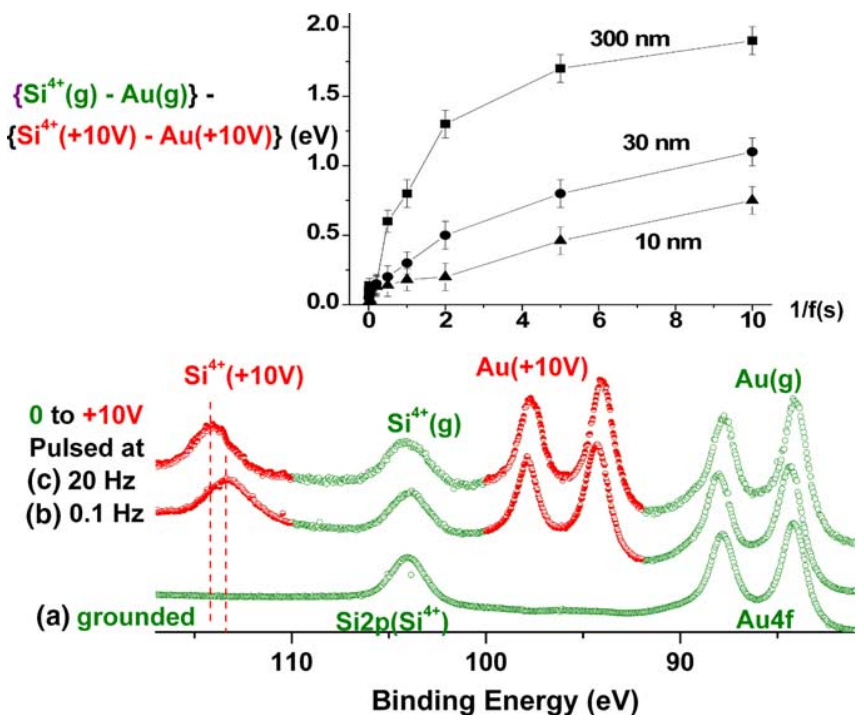

Fig. 3. The same sample as in Fig. 2 under positive pulses with $20 \mathrm{~Hz}$ and $0.1 \mathrm{~Hz}$ frequency. The inset displays the measured binding energy differences plotted against the inverse of the frequency of the applied pulses for three different samples containing 10, 30 and $300 \mathrm{~nm}$ oxide layers, respectively.

Another important observation is the variation of the frequency dependence on the thickness of the oxide layer as displayed in the inset of Fig. 3. The thicker oxide layers display larger variations, and saturate progressively at higher frequencies, indicating that the time constant for charging/discharging is smaller for a thicker dielectric layer compared to a thinner one. We interpret it as being related with the capacitance of the layer (since capacitance is inversely proportional with the thickness) as was also observed in our time-resolved measurements [26,27].

The initial photoemission process and subsequent filling of the core-hole created by outer electrons within the atom are extremely fast (shorter than $10^{-12} \mathrm{~s}$ ) [28] but eventually the hole ends up in the valence band of the oxide which is apparently filled in a much slower time scale $\left(10^{-3}-10^{1} \mathrm{~s}\right)$ similar to the time-dependent leakage currents observed in metal-oxide-semiconductor systems under stress or with aging [29-32]. Similar observations were also reported using scanning capacitance microscopy (SCM) [33].

In short, by pulsing the sample at different frequencies, we effectively cause different extent of charging, hence probe the response time of the dielectric layer. Accordingly, thicker dielectric layers (having smaller capacitance) responds faster when compared with thinner ones. The method is simple, general, and is a non-contact technique, which can easily be extended to include phase measurements and/ or other relevant parameters. Overall, we expect the technique to be especially useful in analysis of fragile organic layers, like self assembled monolayers (SAMs), or nano- structured materials where electrical measurements are difficult.

\section{Acknowledgements}

We thank TUBA (Turkish Academy of Sciences) and TUBITAK (Grant No.: TBAG-2261) for partial financial support.

\section{References}

[1] G. Johansson, J. Hedman, A. Berndtsson, M. Klasson, R. Nilsson, J. Electron. Spectrosc. Relat. Phenom. 2 (1973) 295.

[2] T. Dickinson, A.F. Povey, P.M.A. Sherwood, J. Electron Spectrosc. Relat. Phenom. 2 (1973) 441.

[3] R.T. Lewis, M.A. Kelly, J. Electron Spectrosc. Relat. Phenom. 20 (1980) 105

[4] T.L. Barr, Crit. Rev. Anal. Chem. 22 (1991) 229.

[5] A. Cros, J. Electron Spectrosc. Relat. Phenom. 59 (1992) 1.

[6] J. Cazaux, J. Electron Spectrosc. Relat. Phenom. 105 (1999) 155.

[7] P.E. Larson, M.A. Kelly, J. Vac. Sci. Technol. A 16 (1998) 3483.

[8] M.P. Seah, in: D. Briggs, M.P. Seah (Eds.), Practical Surface Analysis, second ed., vol. 1, Wiley, Chichester, NY, 1999, p. 541.

[9] W.M. Lau, J. Appl. Phys. 65 (1989) 2047.

[10] W.M. Lau, Appl. Phys. Lett. 54 (1989) 338.

[11] W.M. Lau, J. Appl. Phys. 67 (1990) 1504.

[12] W.M. Lau, S. Jin, X.W. Wu, S. Ingrey, J. Vac. Sci. Technol. B 8 (1990) 848.

[13] W.M. Lau, X.W. Wu, Surf. Sci. 245 (1991) 345.

[14] R.W.M. Chan, R.W.M. Kwok, W.M. Lau, J. Appl. Phys. 79 (1996) 3635.

[15] R.W.M. Chan, R.W.M. Kwok, W.M. Lau, H. Yan, S.P. Wong, J. Vac. Sci. Technol. A 15 (1997) 2787.

[16] J.H. Thomas III, C.E. Bryson, T.R. Pampalone, J. Vac. Sci. Technol. B 6 (1988) 1081.

[17] A. Ermolieff, S. Deleonibus, S. Marthon, B. Blanchard, J. Piaguet, J. Electron. Spectrosc. Relat. Phenom. 67 (1994) 409.

[18] F.H. Bell, O. Joubert, J. Vac. Sci. Technol. B 15 (1997) 88.

[19] J.D. Miller, W.C. Harris, G.W. Zajac, Surf. Interface Anal. 20 (1993) 977.

[20] K. Shabtai, I. Rubinstein, S.R. Cohen, H. Cohen, J. Am. Chem. Soc. 122 (2000) 4959.

[21] I. Doron-Mor, A. Hatzor, A. Vaskevich, T. van der Boom-Moav, A. Shanzer, I. Rubinstein, H. Cohen, Nature 406 (2000) 382.

[22] N.J. Havercroft, P.M.A. Sherwood, Surf. Interface Anal. 29 (2000) 232.

[23] B. Ulgut, S. Suzer, J. Phys. Chem. B 107 (2003) 2939.

[24] S. Suzer, Anal. Chem. 75 (2003) 7026.

[25] F. Karadas, G. Ertas, S. Suzer, J. Phys. Chem. B 108 (2004) 1515.

[26] U.K. Demirok, G. Ertas, S. Suzer, J. Phys. Chem. B 108 (2004) 5179.

[27] G. Ertas, U.K. Demirok, A. Atalar, S. Suzer, Appl. Phys. Lett. 86 (2005) 183110.

[28] S. Iwata, A. Ishizaka, J. Appl. Phys. 79 (1996) 6653.

[29] O.L. Curtis, J.R. Srour, J. Appl. Phys. 48 (1977) 3819.

[30] R.C. Hughes, Phys. Rev. B 15 (1977) 1511.

[31] T. Wang, T.E. Cheng, L.P. Chiang, C.H. Wang, N.K. Zons, C. Huang, IEEE Trans. Electron Dev. 45 (1998) 1511.

[32] C.J. Kang, G.H. Buh, S. Lee, C.K. Kim, K.M. Mang, C. Im, Y. Kuk, Appl. Phys. Lett. 74 (1999) 1815.

[33] M. Bourcerie, J.C. Marchetaux, A. Boudou, Appl. Phys. Lett. 55 (1989) 2193. 